\title{
THE EFFECTS OF THE COACH-ATHLETE WORKING ALLIANCE ON AFFECT AND BURNOUT AMONG HICH LEVEL COACHES
}

\author{
Kenneth Myhre, $1, \mathrm{~A}, \mathrm{~B}, \mathrm{C}, \mathrm{D}$ Frode Moen $2, \mathrm{~A}, \mathrm{~B}, \mathrm{C,}, \mathrm{DE}$ \\ ${ }^{1}$ Norwegian University of Science and Technology, Department of Neuroscience, Center for Elite Sports Research, Norway \\ ${ }^{2}$ Norwegian University of Science and Technology, Department of Education, Center for Elite Sports Research, Norway

 \\ Address for coprespondence: \\ Kenneth Myhre \\ Norwegian University of Science and Technology \\ Department of Neuroscience, Center for Elite Sports Research \\ N-7026 Trondheim, Norway \\ E-mail: kenneth.myhre@ntnu.no
}

\begin{abstract}
Ahstract Research suggests that the numbers of coaches who are suffering from burnout symptoms are considerably high among coaches in elite sport. In this study, the authors explore the effects of the coach-athlete working alliance on positive- and negative affect and burnout in a group of high-level coaches. An online survey, consisting of the Working Alliance Inventory-Short Version, the Positive and Negative Affect Schedule and the Maslach Burnout Inventory, was completed by a sample of 299 coaches working with elite athletes or junior elite athletes. Data analysis was conducted using structural equation modelling. The model explained $57 \%$ of the variance in cynicism, $32 \%$ of the variance in reduced sense of accomplishment and $26 \%$ of the variance in exhaustion. These effects mainly derived from positive affect and negative affect. However, working alliance showed a significant indirect effect on all three dimensions of burnot through the mediating variables positive affect and negative affect. These results are discussed in a cognitive activation-perspective.
\end{abstract}

Key Worlds cognitive activation theory, cynicism, sense of accomplishment, exhaustion, coach-athlete relationship

\section{Introduction}

Coaches who are working with athletes who aim to reach a high level in their sport, are required to put a lot of effort and endeavor into their work to develop their athletes towards successful performances (Olusoga, Butt, Hays, Maynard, 2009). This makes coaching a potentially rewarding activty, due to the joy of working with aspiring athletes, the challenge of building successful performance programs, the satisfaction derived from teaching sport skills and the joy and exuberance when winning a contest or achieving ambiguous goals. Such coaching experiences should stimulate positive affect, since they are resulting from successful coaching endeavors (Reme, Eriksen, Ursin, 2008). At the same time, environments in which coaches of high performance athletes are working, are typically achievement oriented and competitive (Hanton, Fletcher, Coughlan, 2005), and coaches have 
to cope with performance-associated stressors both related to their own performance and the development and performances of their athletes (Fletcher, Scott, 2010). Due to this, strain to work in such environments can potentially become a demanding and consuming endeavor, as coaches might experience performance impairments among their athletes, working with unmotivated athletes, experience goals that are not reached, performance programs that fails, and relational difficulties with their athletes and other co-workers (Price, Weiss, 2000). Thus, coaches who are working with high performance athletes can potentially experience considerable loads from negative affect responses because of being unable to handle effectively situational demands in their role (Ursin, Eriksen, 2004). Research claims that there is a close relationship between stress and affect (Hamama, Ronen, Schachar, Rosenbaum, 2013; Lazarus, Folkman, 1984), and high performance coaches might therefore be in danger of developing symptoms of burnout, because of to heavy stress loads over time. Disturbingly for elite sports, research suggests that the numbers of coaches who are suffering from burnout symptoms are considerably high among elite sport coaches (Bentzen, Lemyre, Kenttä, 2015; Hjälm, Kenttä, Hassmén, Gustafsson, 2007). This represents a possible threat with regard both to coach longevity and productivity (Kelley, 1994; Raedeke, Woodard, Granzyk, 2002), and thereby for the performance and development of their athletes (Cavanagh, 2006; Jowett, 2007).

Interestingly in this regard, coaches' relational capabilities is claimed to be one of the most crucial variables for more or less successful coaching (Cavanagh, 2006; Côté, Gilbert, 2009; Jones, 2006; Jowett, 2007). A helping and supportive coach-athlete relationship is seen as essential to achieve successful developmental and performance outcomes in athletes (Benson, Scales, Hamilton, Sesma, 2006). Based on this, the present study will aim to investigate how coaches' percedived working alliance with their athletes are associated with positive and negative affect and the burnout syndrome.

\section{Theoretical Background}

\section{The coach-athlete relationship}

The coach-athlete relationship is often defined by a mutual and causal interdependence between coaches' and athletes' feelings, thoughts and behaviors (Jowett, 2008; Jowett, Cockerill, 2002; Moen, 2012). The importance of an emotional attachment between coaches and their athletes is emphasized in sport science, and the most important tool to establish depth of the coach-athlete emotional attachment is claimed to be the coach's relational capabilities (Jowett, Ntoumanis, 2004). Interestingly, research claims that dysfunctional relationships often are missing the emotional attachment between coaches and athletes, and that such relationships are claimed to be at a dead end (Vargas-Tonsing, Guan, 2007). Several studies also show that both coaches and athletes are aware of the importance of a coach's relational capabilities (Moen, Verburg, 2012; Moen, Garland, 2012; Moen, Federici, Klemetsen, 2013; Moen, Federici, 2013; Moen, Sandstad, 2013; Moen, Federici, 2016).

With regard to the study of coach-athlete relationship in sport science, the constructs of the three C's "Closeness", "Commitment" and "Complementarity" is a well-accepted concept (Jowett, Cockerill, 2002; Jowett, Ntoumanis, 2004). Closeness describes the depth of the coach-athlete emotional attachment in the relationship, commitment reflects coaches and athletes' intention or desire to maintain their relationship over time, and complementarity defines to what degree the relationship is perceived as cooperative and effective (Jowett, Cockerill, 2002). Although widely used in varying sport settings, one could ague that when approaching a setting where athletes aim to develop to their very highest potential, the constructs of the three C's misses to give an explicit measure of two crucial factors: coach-athlete agreement on what goals they are working towards, and the plan of 
action for how to reach these goals. Goal-orientation and task focus are crucial in a change-inducing coach-athlete relationship (Weinberg, Butt, 2014), and it would therefore be interesting to measure these factors more precisely when conducting the relationship among coach-athlete.

Interestingly, research from the clinical field claims that effectiveness and success in a change-inducing relationship is also suggested to rely on the cooperation between the person offering help and the person who seeks help (Bordin, 1979; Horvath, Greenberg, 1989). We would argue that the coach-athlete relationship in high-level sport could be considered as a change-inducing relationship. Such relationships are defined as a working alliance between the helper (therapist) and the person who seeks help (client), and a Working Alliance Inventory (WAI) scale is developed to measure these important characteristics (Horvath, Greenberg, 1989). It was originally designed to measure the strength of the working alliance within therapeutic relationships (Horvath, Greenberg, 1985). However, WAI is later adapted to other helping relationship contexts, like for example supervision (Bahrick, Russel, Salmi, 1991). We hereby suggest using this inventory in the field of high-level sport, with the coach considered as the "helper", and the athlete considered the "help-seeker".

WAI is based on Bordin's (1979) model of the therapeutic working alliance, which is conceptualized trough the three terms "goals", "tasks" and "bonds". In the working alliance theory, goals are the objectives for the collaboration, and are considered the desired outcome from the helping relationship that is established between the therapist and client (Bordin, 1994). The key regarding goals is to reach a high level of agreement or mutuality between the therapist and the client. Tasks are the behaviors and cognitions engaged in by both the therapist and client in the cooperation process. In the sport setting then, a functional coach-athlete relationship is where both parts perceive these tasks applicable and beneficial (Bordin, 1979). Bonding is related to the level of "partner compatibility", which develops from the interaction between coach and athlete in the activities they are involved in (Bordin, 1994). A high level of bonding is expressed as mutual liking and trusting, and a feeling of common purpose and understanding between coach and athlete (Bordin, 1994; Horvath, Greenberg, 1989).

\section{Affect responses}

As opposite to the positive effects of a well-established coach-athlete helping relationship, Goodger, Gorely, Harwood and Lavallee (2007) suggest that negative stress related to for example relationships issues or negative perceived performance outcomes of athletes, correlates positively with burnout among coaches. According to the "Cognitive Activation Theory of Stress" (Ursin, Eriksen, 2004), situations considered unfamiliar or out of control, causes an "alarm" in the body which leads to a homeostatic imbalance. If such a situation lasts over time, and the coach does not have the necessary coping resources, this stress can become negative and destructive, as stress further is linked to psychosomatic complaints, exhaustion and depression (Crawford, Henry, 2004). Based on this, it is likely to expect that the psychological strain and loss of control experienced if failing to establish a functioning working alliance, with subsequent adversely effect on the athletes development and performance, could cause negative stress responses in coaches (Cavanagh, 2006; Côté, Gilbert, 2009; Jones, 2006; Jowett, 2007). However, if the coach has the necessary resources to cope with the situational demands, short periods of stress can actually be positive and developmental (Lazarus, Folkman, 1984), and thus serve as a buffer against destructive, negative stress (Kahn, Byosiere, 1992).

Interestingly, it is previously suggested that positive stress stimulates positive affect, whereas negative stress stimulates negative affect (Hamama, Ronen, Schachar, Rosenbaum, 2013; Lazarus, Folkman, 1984; Crawford, 
Henry, 2004). In this regard, negative affect refers to feelings of sadness and lethargy, anger, contempt, disgust, guilt, fear and nervousness (Watson, Clark, Tellegen, 1988). Positive affect, on the other hand, is linked to enthusiasm, being high in energy, fully concentrated and pleasurable engagement (Watson, Clark, Tellegen, 1988). With this in mind, it could be assumed that a well-functioning coach-athlete relationship will stimulate positive affect among coaches, while if the working alliance does not function well, it could lead to negative affect for the coaches. When further knowing that any factor associated with elevated stress levels may be linked to burnout (Schaufeli, Buunk, 2003), it is likely to assume a link between coach-athlete working alliance and burnout mediated by affect among coaches.

\section{Burnout}

According to Maslach and Jackson (1984), burnout is a psychological syndrome that is likely to occur in individuals who work with people in some capacity. The development of the coach burnout construct commonly focuses on three central dimensions; "emotional and physical exhaustion", "cynicism", "reduced sense of accomplishments". Exhaustion is the core component in coach burnout, and is linked a feeling of fatigue and exhaustion, both physically and emotionally, associated with their practice (Gustafsson, Kenttä, Hassmén, 2011; Raedeke, Smith, 2009). The cynicism dimension refers to a negative, unsympathetic or detached orientation to various aspects of one's practice, and is considered to be a strategy to avoid stressing situations, and make the demands of the situation more manageable (Lundkvist, Stenling, Gustafson, Hassmén, 2014). The dimension of reduced sense of accomplishment refers to a feeling of being incompetent or to an experience of lack in productivity, efficacy and achievements. Demanding work situations that causes exhaustion or cynicism is also likely to impede one's sense of accomplishment (Maslach, Schaufeli, Leiter, 2001).

\section{The present study}

Literature on occupational stress suggests that burnout occurs from exposure to chronic stress over time (Schaufeli, Buunk, 2003). Despite this, in a review of factors contributing to burnout, Schaffran, Altfeld and Kellmann (2016) did not find any studies investigating relations between coach-athlete working alliance and coach burnout.



Figure 1. Hypothesized model 
Therefore, the aim of this article is to explore relations between working alliance, affect and burnout among Norwegian sport coaches working with athletes on a high level. It is hypothesized that working alliance predicts positive affect positively, and negative affect negatively. Further, it is expected that positive affect predicts burnout negatively, and that negative affect predicts burnout positively. The model is shown in Figure 1.

\section{Material and methods}

Eight hundred and seventy six coaches at various levels were invited to participate in a survey. Participants were recruited from exercising databases at Norwegian Olympic and Paralympic Committee and Confederation of Sports. One week ahead of distribution of the survey, participants were contacted via email and given information about why they were selected to participate in the survey, the background and purpose of the study, that all the data would be kept confidential, that participation was voluntary, and that the Norwegian Social Science Data Services (NSD) had approved the project. Participants gave their consent to participate in the study by checking for read and accepted the consent form on the first page of the survey.

A structured questionnaire consisting of five different parts was used for the data collection. All measurements used in this study were based on previously developed scales proven to hold both satisfactory validity and reliability. The measurements were originally in English, but were translated into Norwegian and slightly adjusted for the purpose of this study by the authors. Part 1 of the questionnaire covered general variables such as gender, age, type of sport, level of coaching, years of coaching experience and hours of practice per week. Part 2 consisted of the "Working Alliance Inventory-Short Version", part 3 consisted of the "Positive and Negative Affect Schedule", while part 4 the "Maslach Burnout Inventory-General scale".

\section{Working Alliance Inventory}

A customized version of the Short Version-Working Alliance Inventory (Tracey, Kokotovic, 1989) was used to assess coach- athlete relationship characteristics. The WAI was adapted to the coach-athlete context inspired by Bahrick et al. (1991). Terms such as "therapist" and "client" were in the case of this study changed to "coach" and "athlete," and references to "client problems" were changed to "athlete issues" or "athlete concerns". WAI contains 12 items, covering three dimensions: the "goal dimension" (i.e. My athlete and I work on mutually agreedupon goals), the "task dimension"(i.e. My athlete and I agree about the steps the athlete need to take to improve in his sport), and the "bonding dimension" (i.e. There is mutual trust between my athlete and me). The coaches answered each item on a 7-point Likert scale ranging from 1 = "never" to 7 = "always". The construct validity of The Short Version - Working Alliance Inventory has previously been established by confirmatory factor analysis, and validation studies of the WAI scale have proven good construct validity and high reliability (Corbiére, Bisson, Lauzon, Ricard, 2006; Tracey, Kokotovic, 1989). The Cronbach's alpha for the total measurement in this study was 0.88 , while for the sub-dimensions goal, task and bond it was $0.62,0.80$ and 0.80 respectively.

\section{Positive and Negative Affect Schedule}

The Positive and Negative Affect Schedule (PANAS) (Watson, Clark, Tellegen, 1988) was used to measure positive and negative affect. This scale has previously reported strong validity with measures like general distress and dysfunction, depression and anxiety (Watson et al., 1988). PANAS comprises two scales, each with ten descriptors representing different emotions, that measures positive affect (i.e. excited - strong - proud) and 
negative affect (i.e. upset - nervous - irritable) respectively. The coaches were asked to rate the extent to which they have experienced each particular emotion within the last week as a coach, responding on a 5-point Likert scale ranging from $1=$ "not at all" to $5=$ "very much". The PANAS has strong reported validity with measures as general distress and dysfunction, depression and state anxiety (Watson, Clark, Carey, 1988). The Cronbach's alpha for the measurement in this study was 0.87 (positive affect) and 0.87 (negative affect).

\section{Maslach Burnout Inventory}

Burnout was measured with the Norwegian version of Maslach Burnout Inventory - General scale (Richardsen, Martinussen, 2005; Schaufeli, Leiter, Maslach, Jackson, 1996), consisting of three subscales. Exhaustion was measured with five items (e.g., "I feel emotionally drained from my work"), cynicism was measured with five items (e.g., "I have become less interested in my work since I started this job"), and personal accomplishment was measured with six items (e.g., "I can effectively solve the problems that arise in my work"). The latter sub scale was reversed, and labeled "Reduced Personal Accomplishment". The coaches responded on a 7-point Likert scale with respect to how often they experience each feeling, ranging from 0-6 where $0=$ "never", 1 = "a few times a year or less", 2 = "once a month or less", 3 = "a few times a month", 4 = "once a week", 5 = "a few times a week", and $6=$ "every day". The MBI has previously been proven as reliable and valid measure for burnout in various professions (Schaufeli, Leiter, Kalimo, 1995; Maslach, Jackson, Leiter, 1996). The Cronbach's alpha for the total measurement of burnout in this study was 0.82 , while for the sub-dimensions exhaustion, cynicism and reduced personal accomplishment it was $0.86,0.67$ and 0.79 respectively.

\section{Data Analysis}

The data were first analyzed by examining the correlations between variables using Pearson correlational coefficient. Further, to investigate the quality of the measurement instruments and to determine the zero-order correlations between the variables in the hypothesized model, a confirmatory factor analysis (CFA) was used. Subsequently, the proposed model was tested with structural equation modeling (SEM). Both the CFA and the SEM was conducted using the Amos 23 program (Arbuckle, 2014). Following the standard approach in most latent variable models, the first indicator of each scale was used to set the metric of the latent variables (Brown, 2006). In the CFA and SEM analysis, a maximum likelihood estimator (MLR) was used, due to its robustness towards violations of the multi-normality assumptions a maximum (Brown, 2006).

Model fit was assessed using the CFI, IFI, TLI and RMSEA indices, as well as the chi-square test. With regard to the CFI, IFI, and TLI indices, the analysis in this study relied on Byrne (2010) and Hu and Bentler (1999), suggesting that values above 0.90 indicate an acceptable fit, and values above 0.95 indicate a good fit of the data. Further, according to Hu and Bentler (1999) and Tabachnick and Fidell (2007), a RMSEA value of 0.06 or less reflects a good fit. When the goodness of fit is adequate, the plausibility of the proposed relations among the constructs is supported.

\section{Results}

Out of the 876 coaches who were asked to participate in the investigation, 510 completed the data collection, which gave a response rate of $58.2 \%$. Among the 510 coaches who completed a questionnaire, 299 was identified as high competitive level coaches, as they reported to be coaching elite athletes or junior elite athletes. The other 211 coaches was excluded from the analysis conducted for this particular study, as they reported to coach athletes on lower levels. 
Among the 299 high level coaches, 46 were women and 253 were men. Their mean age was $41.1 \pm 10.4$ years, and they had an average of $15.5 \pm 9.4$ years of coaching experience. They reported to spend on average 24.0 \pm 17.4 hours per week on their work as a coach. 110 coaches had their role as a full time job, 94 worked part time as coaches, whereas 95 had their coacher role as volunteers. The coaches represented a broad variety of sports, with cross-country skiing $(n=75)$, handball $(n=55)$, athletics $(n=37)$, swimming $(n=20)$, cycling $(n=16)$, biathlon $(n=14)$ and soccer $(n=13)$ as the most frequently reported sports. $<5$ coaches worked with athletes in alpine skiing, wrestling, dance, golf, ice hockey, Nordic combined, orienteering, rowing, sailing, ski jumping, ice skating, snowboard, taekwondo, tennis, gymnastics, weight lifting and volleyball.

\section{Corpelations and descriptive statistics}

In Table 1, the correlations between the variables in this study is presented, as well as the possible maximum scores, statistical means, standard deviations, and Cronbach's alphas. The zero order correlations between the variables in this study varies from zero $( \pm 0.09$ to 0.18$)$ to strong $( \pm 0.37$ to 0.88$)$ positive and negative relationships. The Cronbach's alphas of the variables in this study varied from excellent to acceptable. Except for the correlations between the sub-dimensions of working alliance and burnout, the strongest correlation exerted was between burnout and positive affect (negative), and reduced accomplishment and positive affect (negative), followed by the correlation between burnout and working alliance (negative).

Table 1. Pearson correlations and descriptive statistics of all the variables measured in this study

\begin{tabular}{|c|c|c|c|c|c|c|c|c|c|c|}
\hline Variable & 1 & 2 & 3 & 4 & 5 & 6 & 7 & 8 & 9 & 10 \\
\hline 1. Working alliance & - & & & & & & & & & \\
\hline 2. Working alliance - Task & $0.88^{* *}$ & - & & & & & & & & \\
\hline 3. Working alliance - Bond & $0.79^{* *}$ & $0.64^{\star *}$ & - & & & & & & & \\
\hline 4. Working alliance - Goal & $0.83^{* *}$ & $0.57^{\star \star}$ & $0.42^{* *}$ & - & & & & & & \\
\hline 5. Positive affect & $0.29^{* *}$ & $0.21^{* *}$ & $0.31^{* *}$ & $0.22^{* *}$ & - & & & & & \\
\hline 6. Negative affect & $-0.31^{* *}$ & $-0.33^{\star *}$ & $-0.15^{* *}$ & $-0.29^{* *}$ & $0.16^{\star *}$ & - & & & & \\
\hline 7. Burnout & $-0.37^{\star *}$ & $-0.26^{\star *}$ & $-0.31^{* *}$ & $-0.35^{\star *}$ & $-0.42^{\star *}$ & $0.38^{\star *}$ & - & & & \\
\hline 8. Burnout - Cynicism & $-0.28^{\star *}$ & $-0.21^{* *}$ & $-0.23^{\star *}$ & $-0.25^{\star *}$ & $-0.31^{* *}$ & $0.33^{* *}$ & $0.78^{* *}$ & - & & \\
\hline 9. Burnout - Reduced accompl. & $-0.32^{* *}$ & $-0.18^{* *}$ & $-0.33^{\star *}$ & $-0.29^{* *}$ & $-0.42^{* *}$ & $0.12^{*}$ & $0.60^{* *}$ & $0.20^{* *}$ & - & \\
\hline 10. Burnout - Exhaustion & $-0.19^{* *}$ & $-0.16^{\star *}$ & -0.11 & $-0.20^{* *}$ & $-0.17^{* *}$ & $0.36^{* *}$ & $0.76^{* *}$ & $0.49^{* *}$ & 0.09 & - \\
\hline Maximum score & 7 & 7 & 7 & 7 & 10 & 10 & 7 & 7 & 7 & 7 \\
\hline Number of items & 12 & 4 & 4 & 4 & 10 & 10 & 16 & 5 & 6 & 5 \\
\hline Mean & 5.95 & 5.84 & 6.15 & 5.85 & 4.05 & 1.92 & 2.28 & 2.18 & 2.07 & 2.65 \\
\hline Standard deviation & 0.55 & 0.65 & 0.56 & 0.78 & 0.54 & 0.66 & 0.67 & 0.95 & 0.82 & 1.07 \\
\hline Cronbach's alpha & 0.88 & 0.80 & 0.80 & 0.62 & 0.87 & 0.87 & 0.81 & 0.67 & 0.79 & 0.86 \\
\hline
\end{tabular}

${ }^{* *} p<0.01,{ }^{*} p<0.05$. The estimates are based on the observed data.

\section{Measurement model (CFA)}

To investigate the measurement model and the relations between the variables, a CFA of the latent variables was conducted. First, a preliminary CFA was applied for the models of each variable that was studied. A satisfactory model fit was not achieved due to high complexity in relation to sample size when Negative affect and Positive affect 
were entered as first-order latent variables with ten indicators each (each indicator corresponded to an item from the PANAS scale). The same result applied for working alliance, when entered as a second-order latent variable with "task", "goal and "bond" as primary factors (each containing four indicators, conform to the items in the WAI scale). With regard to Burnout, satisfactory model fit was achieved when each of the sub-dimensions "cynicism", "reduced sense of accomplishment" and "exhaustion" was set as first-order latent variables containing five, six and five indicators respectively (conform to the items of the MBI scale).

To reduce complexity and achieve better fit for the models of positive affect, negative affect and working alliance, a parceling method was applied. Parceling involves using composite scores derived from multiple individual scale items, and is a commonly used method in structural equation modeling (Landis, Beal, Tesluk, 2000). It has with advantages such as higher sample-size-to-estimated-paths ratios, increased reliability of manifest indicators and less violation of normality assumptions (Bandalos, Finney, 2001). For the indicators of the latent variables positive affect and negative affect, three parcels constructed from item means of three to four single items was used (Landis, Beal, Tesluk, 2000). For the latent variable working alliance, parcels conform to the primary "task", "goal" and "bond" factors were used, meaning each parcel was constructed from the item means of four single items. With these adjustments, acceptable fit was achieved for all the models of variables under study.

For the final model, a covariance structure model of Figure 1 was specified. This model showed good fit to data $(X 2(171)=118.938, p<0.001$, CMIN/DF = 1.601, RMSEA = 0.045, IFI = 0.969, TLI = 0.959, and CFI = 0.968), and all loadings in the model were significant at $p<0.001$. As showed in Table 2, the correlations between the latent variables varied from low to strong, supporting the zero-order correlations presented in Table 1. The result from the CFA supports the conceptualization of six separate but correlated constructs (see Table 3 ).

Table 2. Correlations between the latent variables included in the covariance structure model

\begin{tabular}{lcccccc}
\hline \multicolumn{1}{c}{ Variable } & 1 & 2 & 3 & 4 & 5 & 6 \\
\hline 1. Working alliance & - & & & & & \\
2. Positive affect & 0.32 & - & & & & \\
3. Negative affect & -0.39 & 0.18 & - & & & \\
4. Cynicism & -0.39 & -0.46 & 0.51 & - & & \\
5. Reduced accomplishment & -0.35 & -0.50 & 0.16 & 0.31 & - \\
6. Exhaustion & -0.23 & -0.21 & 0.42 & 0.77 & 0.13 & - \\
\hline
\end{tabular}

Table 3. Results of the Confirmatory Factor Analysis of Working alliance, Negative affect, Positive affect and dimensions of Burnout

\begin{tabular}{|c|c|c|c|c|c|}
\hline Indicator & Latent variable & $b$ & S.E. & $\beta$ & $p$ \\
\hline 1 & 2 & 3 & 4 & 5 & 6 \\
\hline Task & $\leftarrow \quad$ Working alliance & 1 & & 0.87 & \\
\hline Bond & $\leftarrow$ Working alliance & 0.71 & 0.06 & 0.72 & *** \\
\hline Goal & $\leftarrow$ Working alliance & 0.88 & 0.08 & 0.65 & *** \\
\hline Neg_affect1 & $\leftarrow \quad$ Negative affect & 1 & & 0.77 & \\
\hline Neg_affect2 & $\leftarrow \quad$ Negative affect & 0.82 & 0.06 & 0.72 & *** \\
\hline Neg_affect3 & $\leftarrow \quad$ Negative affect & 0.88 & 0.06 & 0.65 & *** \\
\hline Pos_affect1 & $\leftarrow \quad$ Positive affect & 1 & & 0.84 & \\
\hline
\end{tabular}




\begin{tabular}{|c|c|c|c|c|c|c|}
\hline 1 & & 2 & 3 & 4 & 5 & 6 \\
\hline Pos_affect2 & $\leftarrow$ & Positive affect & 0.95 & 0.06 & 0.81 & $* * \star$ \\
\hline Pos_affect3 & $\leftarrow$ & Positive affect & 0.95 & 0.06 & 0.86 & *** \\
\hline CY1 & $\leftarrow$ & Cynicism & 1 & & 0.69 & \\
\hline $\mathrm{CY} 2$ & $\leftarrow$ & Cynicism & 1.05 & 0.16 & 0.55 & *** \\
\hline $\mathrm{CY} 3$ & $\leftarrow$ & Cynicism & 1.27 & 0.21 & 0.52 & *** \\
\hline RA1 & $\leftarrow$ & Reduced accomplishment & 1 & & 0.69 & \\
\hline RA2 & $\leftarrow$ & Reduced accomplishment & 0.99 & 0.10 & 0.74 & $* * *$ \\
\hline RA3 & $\leftarrow$ & Reduced accomplishment & 1.05 & 0.09 & 0.81 & $* * *$ \\
\hline EX1 & $\leftarrow$ & Exhaustion & 1 & & 0.84 & \\
\hline EX2 & $\leftarrow$ & Exhaustion & 0.87 & 0.07 & 0.77 & *** \\
\hline EX3 & $\leftarrow$ & Exhaustion & 0.80 & 0.06 & 0.75 & $* * *$ \\
\hline
\end{tabular}

${ }^{* * *} p<0.001$.

\section{Structural model}

When acceptable model fit was achieved in the CFA, the hypothesized model displayed in Figure 1 was further tested by means of specifying the relations between the variables as depicted in the model. Bias correction using a bootstrapping procedure with 500 bootstrap samples was applied to calculate the standard errors and confidence intervals of the model parameters.

The path model had acceptable fit to the data $\left(X^{2}(171)=188.938, p<0.001\right.$, CMIN/DF $=1.601$, RMSEA $=$ $0.045, \mathrm{IFI}=0.969, \mathrm{TLI}=0.959$, and $\mathrm{CFI}=0.968)$. The estimates of standardized regression weights and squared multiple correlations are presented in Figure 2, whereas standardized and unstandardized regressions weights, total effects and indirect effects are presented in Table 4.

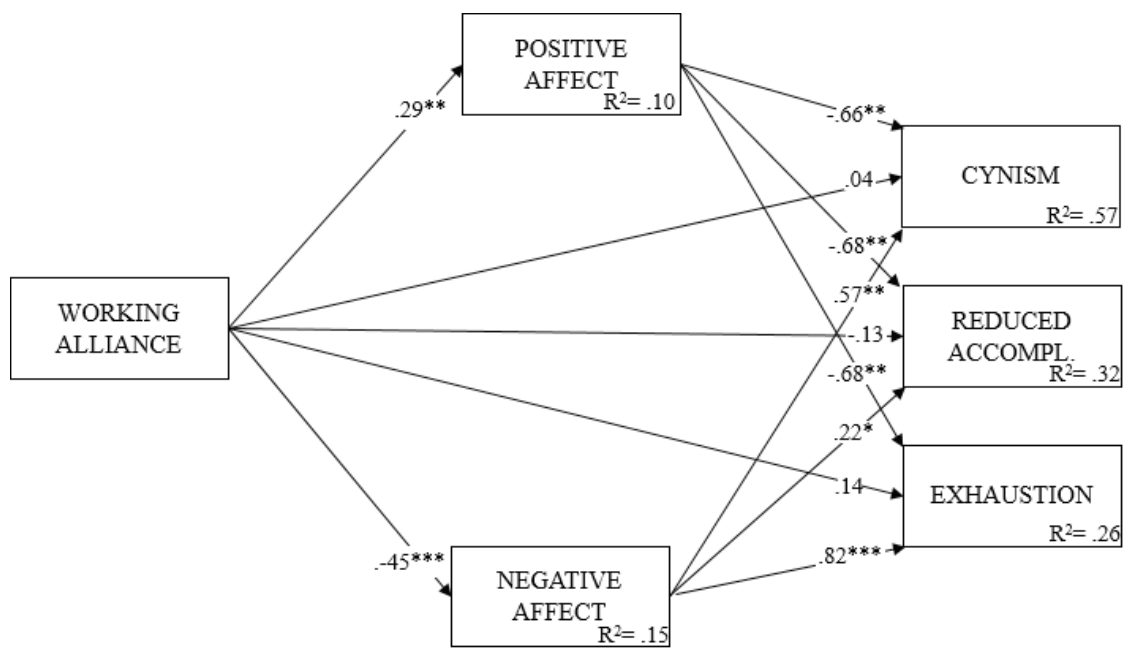

Figune 2. Structural Equation Model (Standardized Solution; $N=299$ ), ${ }^{*} p<0.05 ;{ }^{* *} p<0.01 ;{ }^{* *} p<0.001$ 
Table 4. Unstandardized regressions weights with its standard errors, total effects and indirect effects

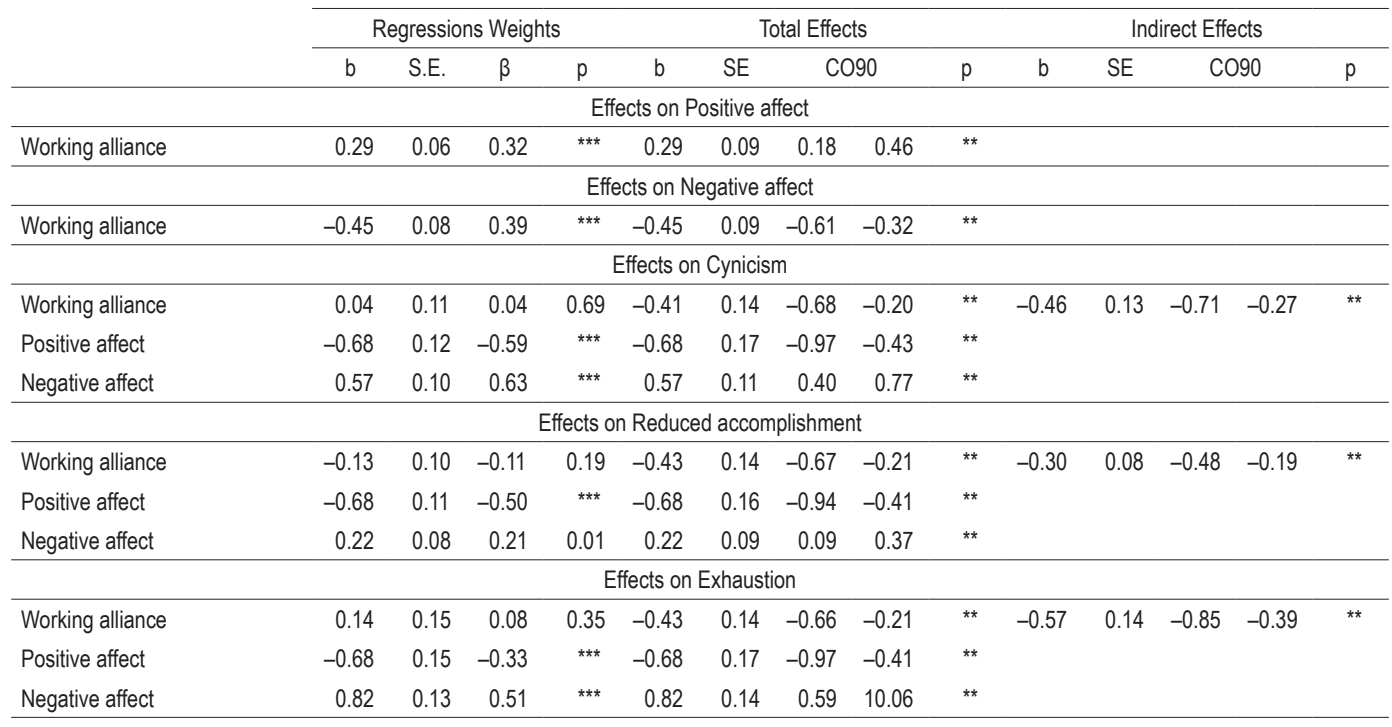

${ }^{* *} p<0.01 ;{ }^{* * *} p<0.001$.

As seen in Figure 2, working alliance affected both positive affect (positively) and negative affect (negatively) significantly. No significant direct effect was revealed between working alliance and any of the burnout dimensions. However, as seen in Table 4, working Alliance showed significant influence by means of indirect effect and total effect on both cynicism, reduced accomplishment and exhaustion $(p<0.01)$.

With regard to the burnout dimensions, both cynicism, reduced accomplishment and exhaustion was positively and significantly influenced by negative affect, and also negatively and significantly influenced by positive affect. In total, the predicting variables explained $57 \%$ of the variance in cynicism, $32 \%$ of the variance in reduced accomplishment and $26 \%$ of the variance in exhaustion.

\section{Discussion}

The purpose of the present study was to test a theoretical model of relations between working alliance, positive affect, negative affect and burnout in a sample of high-level coaches. The findings in this study mainly confirm our hypothesis.

First, our model explained $57 \%$ of the variance in cynicism, $32 \%$ of the variance in reduced accomplishment and $26 \%$ of the variance in exhaustion. These effects are mainly derived from positive affect and negative affect. However, working alliance has a significant indirect effect on all the burnout dimensions through the mediating variables positive affect and negative affect. Further, working alliance explains $10 \%$ of the variance in positive affect and $15 \%$ of the variance in negative affect respectively.

\section{The impact from coaches' perceived working alliance on affect}

In our hypothesized model, we expected working alliance to predict negative affect negatively and positive affect positively. Both of these expectations were confirmed by our findings. A suitable theory that can explain these 
relationships is the Cognitive Activation Theory of Stress (CATS). CATS predicts that if coaches are unable to meet important situational demands in their roles, such as to build-, develop and maintain healthy relationships with their athletes, it can result in negative stress (Ursin, Eriksen, 2004). This means that the physiological and psychological consequences from stress are a response to the cognitive evaluation that coaches accomplish based on their role as coaches. Research claims that there is a close relationship between stress and affect (Hamama, Ronen, Schachar, Rosenbaum, 2013; Lazarus, Folkman, 1984; Ursin, Eriksen, 2004). Thus, coaches believe they have the necessary resources to build-, develop- and maintain healthy relationship with their athletes (positive expectation of the outcome of the situation), the consequence will be a positive affect response (Moen, Federici, Abrahamsen, 2015). On the other hand, the affect response can be negative if the coaches do not expect that they have the capabilities to establish wellfunctioning relationships with their athletes. In other words, positive stress stimulates positive affect, whereas negative stress stimulates negative affect (Crawford, Henry, 2004; Lazarus, Folkman, 1984).

Since both researchers and practitioners highlight the importance an effective coach-athlete relationship to stimulate growth and development of athletes' talents in sport, a possible incapability to meet these demands might most likely impact the level of negative stress in coaches and hence negative affect (Jowett, 2003). More specifically, previous studies with coaches have cited lack of effective communication with their athletes, lack of control over athletes' behaviors and not being able to manage athletes' psychological needs as typical stressors (Frey, 2007; Kroll, Gundersheim, 1982; Olusoga, Butt, 2009). Another study that confirms the negative stress and affect that occurs when coaches are not being able to build healthy relationships with their athletes, shows that coaches were experiencing hurt feelings, lack of commitment and satisfaction as a consequence (Poczwardowski, Barott, Henschen, 2002).

Importantly, a coach-athlete relationship characterized by poor communication and bad relationship quality might ultimately result in interpersonal conflicts (Wachsmuth, Jowett, Harwood, 2017). An interpersonal conflict is a state of imbalance, incongruence, and incompatibility between a coach and an athlete (Hinde, 1997), and involves disagreements and negative emotions (Galtung, 1996; Putnam, Poole, 1987; Thomas, 1992; Wall, Callister, 1995). This type of experiences can be linked to negative affect (Watson, Clark, Tellegen, 1988). Eventually, they also stand as a contrast to the agreement and feeling of common purpose and understanding between coaches and athletes as emphasized in the working alliance-theory (Bordin, 1994).

A well-functioning coach-athlete relationship is, on the other hand, likely to cause positive consequences in form of developmental and performance outcomes in athletes (Benson, Scales, Hamilton, Sesma, 2006).

This represents the potentially rewarding part of the coaching role, related to the joy of building a successful program, satisfaction derived from teaching sport skills successfully and the joy and exuberance when winning a contest or achieving goals. This type of experiences can be linked to feelings like inspiration, enthusiasm, excitement and pride, which again are linked to positive affect (Watson, Clark, Tellegen, 1988).

\section{The impact of coaches' perceived working alliance on burnout}

Further, in our hypothesized model, it was expected that working alliance would predict cynicism, reduced accomplishment and exhaustion directly. These expectations were not confirmed. However, working alliance had a significant indirect effect on all three dimensions of burnout since they are mediated by positive and negative affect. A possible explanation to these results is that it is the coaches' cognitive evaluations of situational demands, such as coping with the coach-athlete relationship, that serve as a potential stressor, or a buffer against so, depending on 
to what extent the working alliance is perceived as effective. For coaches working with athletes who aim to perform on a high level, which applies for the coaches in this study, the process of developing an athletes skills and achieving wanted performance outcomes is the main goal (Lyle, 2002). This puts high demands to quality at every stage of the process, as high performance sport is relying on small margins and the ability to constantly push ones' limits. In the process of developing athlete skills and performance outcomes to the wanted level, it seems important for the coach to experience high levels of task- and goal agreement, and emotional bond to the athletes. A coach who fails in establishing bond with his athletes, and struggling with clarifying goals and tasks, might on the other hand cause an imbalance and interference in the development process. Thus, the way coaches relate situational demands in their roles seems vital for the experienced load that is associated with their roles, and thus the affective response that follows. The load from the actual tasks coaches need to fulfill in their roles is not necessarily decisive.

\section{Impact on the burnout dimensions}

Finally, we expected positive affect to have a negative direct effect on cynicism, reduced accomplishment and exhaustion, and negative affect to have a positive direct effect on the same variables. All of these expectations were confirmed.

The cynicism dimension of burnout reflects the coaches' direct attitudes and feelings towards the job they do with their athletes, and is in a stress perspective viewed as an avoidance strategy to make strenuous situations more manageable for the coach (Lundkvist, Stenling, Gustafsson, Hassmén, 2014). 57\% of the variance in cynicism is explained by the working alliance and affect-variables in this study. Thus, the importance of coach-athlete working alliance clearly stands out as a considerable factor to explain the burnout syndrome among elite coaches. Increased levels of cynicism involves negative, unsympathetic or disconnected orientation to various aspects the coaching practice (Lundkvist, Stenling, Gustafsson, Hassmén, 2014), and might lead coaches to distances themselves from their athletes, which again negatively will influence both the relationship bond and the performance outcome. This might be especially critical in a high-level coach athlete relationship, as the symptoms of cynicism indicate attitudes opposite from the collaboration, close interaction and mutuality emphasized in the working alliance concept (Bordin, 1979). With this in mind, the longitudinal effects of increased cynicism levels back on the working alliance are an interesting theme for further research.

The model in our study explains $32 \%$ of the variance in the reduced accomplishment dimension. The performances of coaches' are often judged by the success of their athletes (Gould, Dieffenbach, 2002). If relying on the suggestions that a helping and supportive coach-athlete relationship is essential to achieve successful developmental and performance outcomes in athletes (Benson, Scales, Hamilton, Sesma, 2006), the negative relationship between working alliance/affect and burnout is not surprising. On the road to achieve success in elite sport, well-defined and common understanding of goals, and a clear common understanding of the tasks are necessary to reach the goals. If this is not established, eventually an imbalance between expectations and outcome of the coaching process might occur, and cause a negative stress reaction for the coach (Schaufeli, Buunk, 2003).

Finally, the model in this study explains $26 \%$ of the variance in exhaustion. This is explained by the working alliance and affect-variables in the model, and thus the importance of a well-established coach athlete working alliance for coaches' physiological and psychological health and perseverance is highlighted. The exhaustion dimension directly relates to the stress part of burnout, and describes exhaustion because of prolonged work-life stress (Schaffran, Altfeld, Kellmann, 2016). 


\section{Relationships between the burnout dimensions}

One interesting issue that has continued to interest burnout researchers and practitioners is the relationships between the three dimensions of burnout, and the development of the burnout syndrome. It is generally assumed that the three burnout dimensions do not develop simultaneously, and hence, knowledge about the causal order of the three burnout dimensions can be relevant for the early recognition of burnout and the identification of "high-risk" people who could be targeted for early, preventive interventions (Maslach, Leiter, 2008; Schaufeli, Enzmann, 1998). It is claimed that the associations among the three dimensions is resulting from an underlying causal process that reflects the development of burnout (Golembiewski, Munzenrider, Stevenson, 1986; Lee, Ashforth, 1996; Leiter, Maslach, 1988; Taris, Le Blanc, Schaufeli, Schreurs, 2005). A possible theory that can be used to discuss possible consequences of the results in this study is the phase model. The phase model claims that depersonalization is experienced first (cynicism) in the process of burning out, since some level of detachment is necessary in helping relationships (Golembiewski, Munzenrider, Stevenson, 1986). Following detachment is depersonalization that undermines performance and ultimately stimulates the emotional strain (Golembiewski, Munzenrider, Stevenson, 1986). Thus, based on this theory the results in this study are interesting, since working alliance, positive affect and negative affect explains $57 \%$ of the variation in cynicism. Cynicism is by some researchers claimed to be the triggering variable in the burnout syndrome, and that both reduced accomplishments and exhaustion subsequently will develop over time (Golembiewski, Munzenrider, Stevenson, 1986). This study has identified the perceived coach-athlete working alliance as an important factor that can be targeted for early, preventive interventions (Maslach, Leiter, 2008; Schaufeli, Enzmann, 1998). However, longitudinal data is needed to conform this finding.

\section{Conclusion and limitations}

It is worth noticing that this study limited by the cross-sectional design used. Such data do not support analyses in causal terms, even though our interpretations are based on previous findings and theoretical analyses. As burnout is described as a slow and gradual process that is expected to change over time, longitudinal examinations might provide greater insights into the development of burnout, and possible contributors in this regard. In addition, the cross-sectional design does not assess directly what causes the affect levels among the coaches. Other limitations should also be taken into account. For example, possible influencing factors such as gender, number of athletes coached, sport and type of professional was not considered in this study. In addition, the reliability of the sub-dimensions "goal" of the WAI and "cynicism" of the MBI showed questionable reliability, and these results should therefore be critically considered.

The effects found in this study suggest that the coach-athlete working alliance to be a significant contributor to burnout in high-level coaches. However, longitudinal research are called for in the future, to examine the effect of coaches' perceived coach-athlete working alliance on affect and burnout over time.

\section{References}

Arbuckle, J.L. (2014). Amos (Version 23.0) [Computer Program]. Chicago: IBM SPSS.

Bahrick, A.S., Russell, R.K., Salmi, S.W. (1991). The effects of role induction on trainees' perceptions of supervision. Journal of Counseling and Development, 434-438. 
Bandalos, D.L., Finney, S.J. (2001). Item parceling issues in structural equation modeling. In: G.A. Marcoulides, R.E. Schumacker (eds.), Advanced structural equation modeling: New developments and techniques. Mahwah, NJ: Lawrence Erlbaum Associates, Inc.

Benson, P.L., Scales, P.C., Hamilton, S.F., Sesma, A. (2006). Positive youth development: Theory, research, and applications. In: W. Damon, R.M. Lerner (eds.), Handbook of child psychology (pp. 894-941). New York: John Wiley.

Bentzen, M., Lemyre, P.N., Kenttä, G. (2015). Changes in motivation and burnout indices in high-performance coaches over the course of a competitive season. Journal of Applied Sport Psychology, 28, 28-48. DOI: 10.1080/10413200.2015.1053160.

Bordin, E.S. (1979). The generalizability of the psychoanalytic concept of the working alliance. Psychotherapy: Theory, Research, and Practice, 16, 252-260.

Bordin, E. (1994). Theory and research on the therapeutic working alliance: New directions. In: A. Horvath, L. Greenberg (eds.), The working alliance: Theory, research and practice (pp. 13-37). New York: Wiley.

Brown, T. (2006). Confirmatory factor analysis for applied research. New York: Guildford.

Byrne, B.M. (2010). Structural equation modeling with AMOS: Basic concepts, applications, and programming (2nd ed.). New York: Routledge Academic.

Cavanagh, M. (2006). Coaching from a systematic perspective: A complex adaptive conversation. In: D.R. Stober, A.M. Grant (eds.), Evidence based Coaching Handbook: putting best practices to work for your clients (pp. 313-354). New Jersey: John Wiley \& Sons.

Côté, J., Gilbert, W.D. (2009). An integrative definition of coaching effectiveness and expertise. International Journal of Sports Science \& Coaching, 4, 307-323.

Corbière, M., Bisson, J., Lauzon, S., Ricard, N. (2006). Factorial validation of a French shortform of the Working Alliance Inventory. International Journal of Methods in Psychiatric Research, 15 (1), 36-45.

Crawford, J.R, Henry, J.D. (2004). The positive and negative affect schedule (PANAS): Construct validity, measurement properties and normative data in a large non-clinical sample. British Journal of Clinical Psychology, 43, 245-265. DOI: 10.1348/ 0144665031752934.

Fletcher, D., Scott, M. (2010). Psychological stress in sports coaches: A review of concepts, research, and practice. Journal of Sport Sciences, 28, 127-137.

Frey, M. (2007). College coaches' experiences with stress - "problem solvers" have problems too. The Sport Psychologist, 21, 38-57.

Galtung, J. (1996). Peace by peaceful means. Oslo-London: Sage Publications and PRIO.

Golembiewski, R.T., Munzenrider, R.F., Stevenson, J.G. (1986). Phases of burnout: developments in concepts and applications. New York: Praeger.

Goodger, K., Gorely, T., Harwood, C., Lavallee, D. (2007). Burnout in sport: A systematic review. The Sport Psychologist, 21, $127-151$.

Gould, D., Dieffenbach, K. (2002). Overtraining, underrecovery, and burnout in sport. In: M. Kellman (ed.), Enhancing recovery: Preventing underperformance in athletes. Champaign, IL: Human Kinetics.

Gustafsson, H., Kenttä, G., Hassmén, P. (2011). Athlete burnout: An integrated model and future research directions. International Review of Sport and Exercise Psychology, 4, 3-24.

Hamama, L., Ronen, T., Schachar, K., Rosenbaum, M. (2013). Links between stress, positive and negative affect, and life satisfaction among teachers in special education schools. Journal of Happiness Studies, 14 (3), 731-751. DOI: 10.1007/s10902-012-9352-4.

Hanton, S., Fletcher, D., Coughlan, G. (2005). Stress in elite sports performers: A qualitative investigation of competition and organizational stressors. Journal of Sports Sciences, 10, 1129-1141.

Hinde, R.A. (1997). Relationships: A dialectical perspective. Hove, UK: Psychology Press.

Hjälm, S., Kenttä, G., Hassmén, P., Gustafsson, H. (2007). Burnout among elite soccer coaches. Journal of Sport Behavior, 30 (4), 415-427.

Horvath, A., Greenberg, L. (1985). The development of the Working Alliance Inventory. In: L. Greenberg, W. Pinsoff (eds.), The psychotherapeutic process (pp. 333-355). New York: Guilford Press.

Horvath, A.O., Greenberg, L.S. (1989). Development and validation of the Working Alliance Inventory. Journal of Counseling Psychology, 36, 223-233.

Hu, L., Bentler, P.M. (1999). Cutoff criteria for fit indexes in covariance structure analysis: Conventional criteria versus new alternatives. Structural Equation Modeling, 6, 1-55. 
Jones, R.L. (2006). How can educational concepts inform sports coaching? In: R.L. Jones (ed.), The sports coach as educator: Reconceptualising sports coaching (pp. 3-13). London: Routledge.

Jowett, S. (2003). When the honeymoon is over: A case study of a coach-athlete relationship in crisis. Sport Psychologist, 17, 444-460.

Jowett, S. (2007) Interdependence analysis and the 3+1Cs in the coach-athlete relationship. In: S. Jowett, Lavallee (eds.), Social Psychology in Sport (pp. 3-14). Champaing, IL: Human Kinetics.

Jowett, S. (2008). Moderators and mediators of the association between the coach-athlete relationship and physical self-concept. International Journal of Coaching Science, 2, 43-62.

Jowett, S., Cockerill, I.M. (2002). Incompatibility in the coach-athlete relationship. In: I.M. Cockerill (ed.), Solutions in sport psychology (pp. 16-31). London: Thomson Learning.

Jowett, S., Ntoumanis, N. (2004). The coach-athlete relationship questionnaire (CART - Q): Development and initial validation. Scandinavian Journal of Medicine and Science in Sports, 14, 245-257.

Kahn, R.L., Byosiere, P.B. (1992). Stress in organizations. In: M.D. Dunnette, L.M Hugh (eds.), Handbook of Industrial and Organizational Psychology (pp. 571-650). Palo Alto, CA: Consulting Psychologists Press.

Kelley, B.C. (1994). A model of stress and burnout in collegiate coaches: Effects of gender and time of season. Research Quarterly for Exercise and Sport, 65, 48-58.

Kroll, W., Gundersheim, J. (1982). Stress factors in coaching. Coaching Science Update, 23, 47-49.

Lazarus, R.S., Folkman, S. (1984). Stress, appraisal, and coping. New York: Springer Pub. Co.

Landis, R.S., Beal, D.J., Tesluk, P.E. (2000). A comparison of approaches to forming composite measures in structural equation models. Organizational Research Methods, 3, 186-207.

Lee, R.T., Ashforth, B.E. (1996). A meta-analytic examination of the correlates of the three dimensions of job burnout. Journal of Applied Psychology, 81, 123-133. DOI: 10.1037/0021-9010.81.2.123.

Leiter, M.P., Maslach, C. (1988). The impact of interpersonal environment of burnout and organizational commitment. Journal of Organizational Behavior, 9, 297-308. DOI: 10.1002/job.4030090402.

Lundkvist, E., Stenling, A., Gustafsson, H., Hassmén, P. (2014). How to measure coach burnout: An evaluation of three burnout measures. Measurement in Physical Education and Exercise Science, 18 (3), 209-226.

Lyle, J. (2002). Sport coaching concepts: A framework for coaches' behaviour. London: Routledge.

Maslach, C., Jackson, S.E. (1984). Burnout in organizational settings. In: S. Oskamp (ed.), Applied social psychology annual: Applications in organizational settings (pp. 133-153). Beverly Hills, CA: Sage.

Maslach, C., Jackson, S.E., Leiter, M.P. (1996). Maslach Burnout Inventory: Manual (6th ed.). Mountain View, CA: Consulting Psychologist Press.

Maslach, C., Leiter, M.P. (2008). Early predictors of job burnout and engagement. Journal of Applied Psychology, 93, 498-512. DOI: 10.1037/0021-9010.93.3.498.

Maslach, C., Schaufeli, W.B., Leiter, M.P. (2001). Job burnout. Annual Review of Psychology, 52 (1), 397-422.

Moen, F. (2012): Subjective beliefs among coaches about how relational factors affect intrinsic motivation, responsibility and development in sport. Athletic Insight Journal, 3 (4), 219-235.

Moen, F., Federici, R. (2013). Coaches' coaching competence in relation to athletes' perceived progress in elite sport. Journal of Education and Learning, 2 (1), 240-252.

Moen, F., Federici, R. (2016). Can athlete-centered coaching stimulate need satisfaction and prevent athlete burnout? International Journal of Sport Management, 68.

Moen, F., Federici, R., Abrahamsen, F. (2015). Examining possible relationships between self-determination and burnout among junior athletes in sport. The International Journal of Coaching Science, 9, 43-58.

Moen, F., Federici, R., Klemetsen, H. (2013). Elite athletes' perceptions of their coaches' coach competencies in nordic combined. The Journal of Excellence, 16, 62-73.

Moen, F., Garland, K. (2012). Subjective beliefs among sport coaches about communication during practice. Scandinavian Sport Studies Forum, 3, 121-142.

Moen, F., Sandstad, H. (2013). Subjective expectations among athletes about coaches in sport. Journal of Human Subjectivity, 11, 135-155.

Moen, F., Verburg, E. (2012). Subjective beliefs among athletes about how relational factors affect intrinsic motivation, responsibility and development in sport. The International Journal of Coaching and Science, 6 (1), 81-100. 
Olusoga, P., Butt, J., Hays, K., Maynard, I.W. (2009). Stress in elite sports coaching: Identifying stressors. Journal of Applied Sport Psychology, 21 (4), 442-459.

Poczwardowski, A., Barott, J.E., Henschen, K.P. (2002). The athlete and coach: Their relationship and its meaning. Results of an interpretive study. International Journal of Sport Psychology, 33 (1), 116-140.

Price, M.S., Weiss, M.R. (2000). Relationships among coach burnout, coach behaviors, and athletes' psychological responses. The Sport Psychologist, 14, 391-409.

Putnam, L.L, Poole, M.S. (1987). Conflict and negotiation. In: F.M. Jablin, L.L. Putnam, K.H. Roberts, L.W. Porter (eds), Handbook of organizational communication (pp. 549-599). Newbury Park, CA: Sage.

Raedeke, T.D., Smith, A.L. (2009). The Athlete burnout questionnaire manual. Morgantown, WV: Fitness Information Technology.

Raedeke, T.D., Warren, A.H., Granzyk, T.L. (2002). Coaching commitment and turnover: a comparison of current and former coaches. Research Quarterly for Exercise and Sport, 73 (1), 73-86.

Reme, S.E., Eriksen, H.R., Ursin, H. (2008). Cognitive activation theory of stress - how are individual experiences mediated into biological systems? Scandinavian Journal of Work, Environment \& Health, 6, 177-183.

Richardsen, A.M., Martinussen, M. (2005). Factorial validity and consistency of the MBI-GS across occupational groups in Norway. International Journal of Stress Management, 12, 289-297.

Schaffran, P., Altfeld, S., Kellmann, M. (2016). Burnout in sport coaches: A review of correlates, measurement and intervention. Deutsche Zeitschrift für Sportmedizin, 67, 121-125.

Schaufeli, W.B., Buunk, B.P. (2003). Burnout: An overview of 25 years of research and theorizing. In: M.J. Schabracq, J.A.M. Winnubst, C.L. Cooper (eds.), The handbook of Work and Health Psychology (pp. 383-425). Chichester: Wiley \& Sons.

Schaufeli, W.B., Leiter, M.P., Kalimo, R. (1995). The Maslach Burnout Inventory-General Survey: A self-report questionnaire to assess burnout at the workplace. In: M.P. Leiter (ed.), Extending the Burnout Construct: Reflecting Changing Career Paths. Symposium, APA/NIOSH conference, Work, Stress, and Health '95: Creating a Healthier Workplace. Washington, DC.

Schaufeli, W.B., Enzmann, D. (1998). The burnout companion to study and practice. A critical analysis. London: Taylor \& Francis.

Schaufeli, W.B., Leiter, M.P., Maslach, C., Jackson, S.E. (1996). The Maslach Burnout Inventory-General Survey. In: C. Maslach, S.E. Jackson, M.P. Leiter (eds.), Maslach Burnout Inventory. Palo Alto, CA: Consulting Psychologists Press.

Tabachnick, B.G., Fidell, L.S. (2007). Using multivariate statistics (5th ed.). Boston, MA: Allyn \& Bacon

Taris, T.W., Le Blanc, P.M., Schaufeli, W.B., Schreurs, P.J.G. (2005). Are there causal relationships between the dimensions of the Maslach Burnout Inventory? A review and two longitudinal tests. Work Stress, 19, 238-255. DOI: 10.1080/02678370500270453.

Tracey, T.J., Kokotovic, A.M. (1989). Factor structure of the Working Alliance Inventory. Psychological Assessment, 1, $207-210$.

Ursin, H., Eriksen, H.R. (2004). The cognitive activation theory of stress. Psychoneuroendocrinology, 29, 567-592.

Vargas-Tonsing, T.M., Guan, J. (2007). Athletes' preferences for informational and emotional pre-game speech content. International Journal of Sport Science \& Coaching, 2 (2), 171-180.

Wachsmuth, S., Jowett, S., Harwood, C.G. (2017). Conflict among athletes and their coaches: what is the theory and research so far? International Review Of Sport And Exercise Psychology, 10 (1), 84-107.

Wall, J., Callister, R. (1995). Conflict and its management. Journal of Management, 21, 515-558.

Watson, D., Clark, L.A., Carey, G. (1988). Positive and negative affectivity and their relation to anxiety and depressive disorders. Journal of Abnormal Psychology, 97, 346-353.

Watson, D., Clark, L.A., Tellegen, A. (1988). Development and validation of brief measures of positive and negative affect: The PANAS scales. Journal of Personality and Social Psychology, 54, 1063-1070.

Weinberg, R., Butt, J. (2014). Goal - setting and sport performance: research fi ndings and practical applications. In: A. Papaioannou, D. Hackfort (eds.), Routledge Companion to Sport and Exercise Psychology. Global Perspectives and Fundamental Concepts (pp. 343-355). London: Taylor \& Francis.

Cite this anticle aS: Myhre, K., Moen, F. (2017). The Effects of the Coach-Athlete Working Alliance on Affect and Burnout Among High Level Coaches. Central European Journal of Sport Sciences and Medicine, 18 (2), 41-56. DOI: 10.18276/cej.2017.2-05. 